Results Results were obtained from all 30 medical schools and for 24 programmes in 23 medical schools providing teaching in 2000/2001. All continue to deliver teaching on last days of life, death and bereavement. This is now mandatory. Generally, this remains a module within a larger course or is fully integrated. Teaching methods remain similar (2013 v 2001): lectures [28 $(93 \%)$ v $21(88 \%)]$, seminars/small group discussion [28 (93\%) v $23(96 \%)]$, video [18 (60\%) v $19(79 \%)]$, case discussion [17 $(57 \%)$ v $23(96 \%)]$, patient addressing students [18 (60\%) v 9 $(38 \%)]$ and role play [16 (53\%) v $22(92 \%)]$. New features are MDT meetings [12/30 (40\%)] and e-learning [14/30 (47\%)]. Teaching is most commonly delivered by medical PC specialists [30 v $24(100 \%)]$, GPs [17 (57\%) v 20 (83\%)] and specialist nurses [24 $(80 \%)$ v $15(63 \%)]$. All major topics are covered to varying degrees. Teaching about PC for young patients remains limited [7 (29 responses 24\%) v 8 (33\%)]. Opportunities for patient contact has increased with 27 (28 respondents 96\%) offering inpatient PC unit/hospice visits compared to 18 in 2001 (75\%). More medical schools are assessing PC learning [25 (83\%) v 6 (25\%)]

Conclusion PC training for medical students continues to evolve. Recent changes are increased patient contact and assessment of PC learning.

\title{
REFERENCE
}

1 Field D, Wee B. Med Educ 2002; 36(8):561-7.

\section{P 056 PALLIATIVE CARE (PC) EDUCATION FOR MEDICAL STUDENTS: HAS IT IMPROVED OVER THE LAST DECADE? A SURVEY OF PC EDUCATION}

Steven Walker, ${ }^{1,2}$ Jane Gibbins, ${ }^{3}$ Stephen Barclay, ${ }^{4}$ Mandy Barnett, ${ }^{5}$ Astrid Adams, ${ }^{6}$ Paul Pees, ${ }^{7}$ Madawa Chandratilake, ${ }^{2}$ Philip Lodge, ${ }^{8}$ Bee Wee ${ }^{6} .{ }^{1}$ Marie Curie Hospice, Hampstead, London, UK; ${ }^{2}$ Centre for Medical Education, University of Dundee, UK; ${ }^{3}$ Cornwall Hospice Care, Royal Cornwall Hospital \& Peninsula Medical School, Truro, UK; ${ }^{4}$ University of Cambridge, Cambridge, UK; ${ }^{5}$ University of Warwick, Coventry, UK; ${ }^{6}$ Sir Michael Sobell House \& University of Oxford, Oxford, UK;

${ }^{7}$ Northumbria Healthcare NHS Foundation Trust \& Newcastle University, Newcastle, UK; ${ }^{8}$ University College London \& Royal Free Hospital, London, UK

\subsection{6/bmjspcare-2014-000654.97}

Background A survey of UK medical schools conducted in 1983, 1994 and 2000/2001 showed an increase in PC teaching time and course diversity. Gaps included limited assessment. ${ }^{1}$

Aims To investigate changes in PC training for medical students at UK medical schools over the last decade.

Methods A web-based questionnaire developed from previous surveys was sent to PC leads in UK medical schools. Responses were compared with those obtained in 2000/2001. The study received ethical approval. 